\title{
There is still seasonality in sudden infant death syndrome in England and Wales
}

\author{
Steven A Julious
}

Medical Statistics and Computing, University of Southampton, Level B, South Academic Block, Southampton General Hospital, Southampton SO16 6YD SA Julious

Correspondence to: Mr SA Julious.

Accepted for publication July 1996

f Epidemiol Commun Health 1997;51:101-102
In England and Wales, the rate of sudden infant death syndrome (SIDS) has being falling constantly from 2.3 deaths per 1000 live births in 1988 to 0.68 in 1993 and $1994 . .^{12}$ The biggest reduction occurred from 1991 to 1992 , when the rate nearly halved from 1.44 to 0.77 . An explanation offered for this sharp reduction is the Back to Sleep campaign, initiated in late 1991, which advised parents to lie their infants on their backs. A major feature of SIDS has been its seasonality. ${ }^{3}$ However, with the recent reductions in the rates some researchers
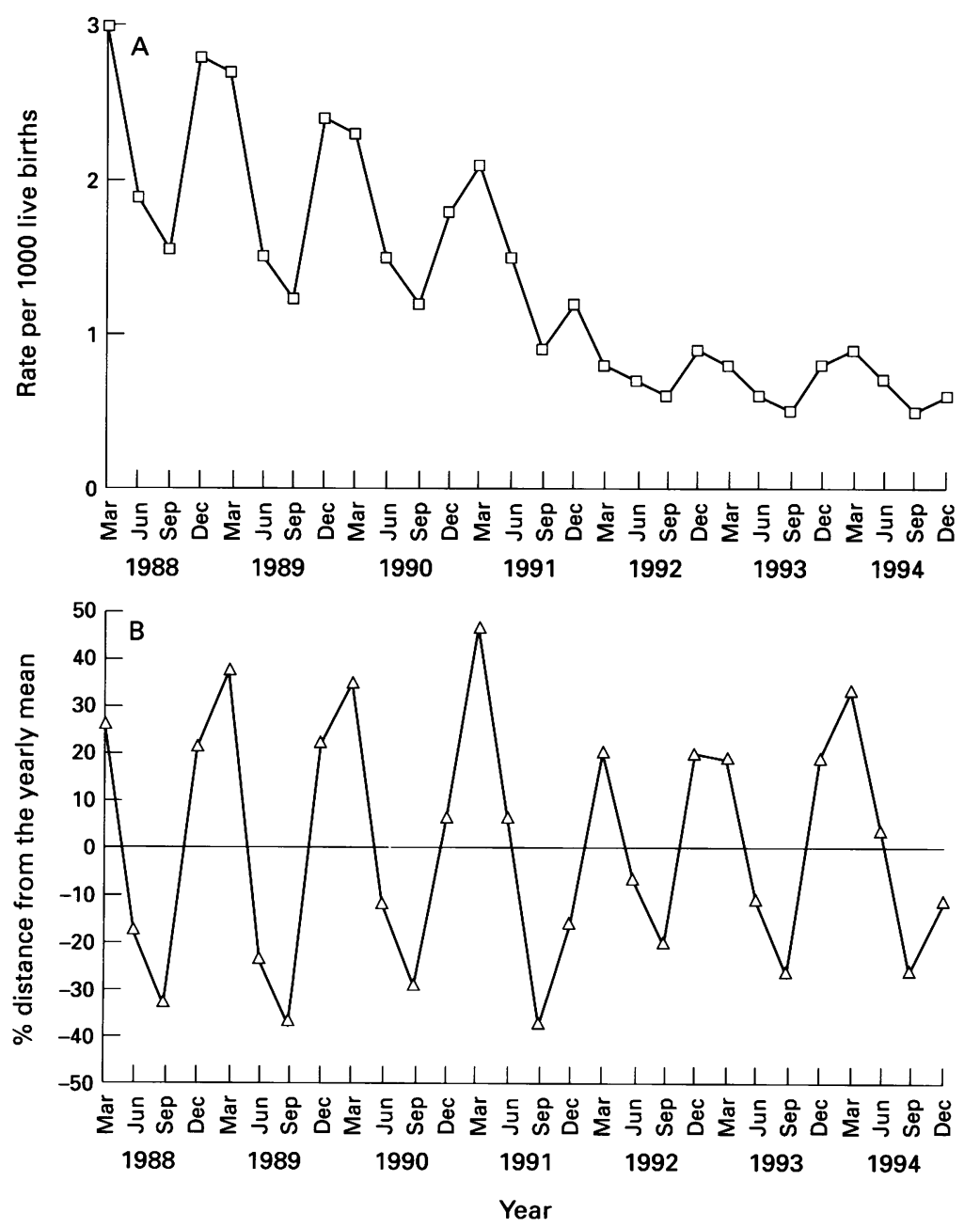

Figure 1 Sudden infant deaths in England and Wales in each quarter from 1988 to 1994. A. Crude rates. B. Percentage above the yearly mean.

have suggested that it is no longer seasonal. ${ }^{45}$ The seasonality of SIDS between the years 1988 and 1994 has been examined.

\section{Methods and results}

The statistics were obtained from previously published data. ${ }^{12}$ These data divide the year into four quarters, January to March, April to June, July to September, and October to December. The rates for these four quarters are plotted to highlight seasonality in the data. Figure 1A shows the crude rates plotted over time. This is equivalent to the graphs used in previous studies. ${ }^{45}$ From this graph authors have concluded that the winter peak has been lost, with the quarterly rates converging after $1991 .^{45}$ This in turn has lead to the inference that there was an interaction between the Back to Sleep campaign and seasonality in SIDS. ${ }^{4}$

The effect of plotting the crude rates is that it 'flattens out' the rates from the later years where values are one third of those of 1988, and any seasonality is hidden. However, it is the proportional (relative) changes in a given year which are the most important. To standardise the rates across years, therefore, for each year the yearly average was subtracted from each quarterly rate and then this difference was divided by the yearly average (the mean being the mean of the four quarters' rates in a given year). Figure $1 \mathrm{~B}$ plots the percentage above and below the mean for each quarter in an individual year. The rates for each year are now on the same scale.

The trends highlighted in figure $1 \mathrm{~B}$ indicate a picture different to that in figure $1 \mathrm{~A}$ where the crude rates were plotted. There is still a winter peak and clear evidence of seasonality. The effect seemed less marked in 1992, although for 1994 the winter peak is the same as for the earlier years. The lowest point for each year lies in the quarter from July to September. Logged rates were then analysed, with the effect for the four quarters entered concurrently into the model with year. Taking the July to September quarter as the baseline (ie, the summer' quarter), the rate ratios are 1.84 (95\% confidence interval $(\mathrm{CI})=1.60,2.13$ ) for January to March, $1.29(\mathrm{CI}=1.12,1.49)$ for April to June and $1.53(\mathrm{CI}=1.33,1.77)$ for October to December (test for equality of rates, $p<0.001$ ) 


\section{Comment}

There is still strong evidence of seasonality in SIDS, with the rate ratios for the first and final quarters of the year being 1.84 and 1.53 when compared to the third quarter. The campaigns concerning sleeping position and smoking appear to have had a marked effect on reducing the overall rates without reducing the seasonality. Previous authors have only examined rates up to 1992 and looked at additive changes, whereas in this paper rates to 1994 are included and proportional changes are examined. Previous research has shown a lag effect of temperature whereby a fall in temperature is followed by an increase in the number of SIDS cases 4-6 days later. ${ }^{3}$ Further investigation of the relationship between SIDS and environmental temperature is therefore required.

Office of Population Census and Surveys. Sudden infant deaths. 1988-92. London: HMSO, 1993. OPCS Monitor Series DH3 93/2

Office of Population Census and Surveys. Sudden infant deaths. 1990-94. London: HMSO , 1995. OPCS Monitor Series DH3 95/3

Murphy MFG, Campbell MJ. Sudden infant death syndrome and environmental temperature: an analysis using vita statistics. F Epidemiol Community Health 1987;41:63-71.

Gilman EA, Cheng KK, Winter HR, Scrag R. Trends in rates and seasonal distribution of sudden infant deaths in England and Wales. BMF 1995;310:631-32

Wigfield R, Gilbert R, Fleming PJ . SIDS: risk reduction measures. Early Human Development 1994;38:161-64. 